\section{Chemical speciation of nanoparticles surrounding metal-on-metal hips $\dagger$}

\author{
Angela E. Goode, ${ }^{a}$ James M. Perkins, ${ }^{a}$ Ann Sandison, ${ }^{b}$ Chithra Karunakaran, ${ }^{c}$ \\ Huikai Cheng, ${ }^{d}$ David Wall, ${ }^{d}$ John A. Skinner, ${ }^{e}$ Alister J. Hart, ${ }^{f}$ Alexandra E. Porter, ${ }^{* a}$ \\ David W. McComb*ag and Mary P. Ryan*a
}

Received 26th April 2012, Accepted 12th June 2012

DOI: $10.1039 / \mathrm{c} 2 \mathrm{cc} 33016 \mathrm{~d}$

Spectromicroscopy of tissue surrounding failed $\mathrm{CoCr}$ metalon-metal hip replacements detected corroded nanoscale debris in periprosthetic tissue in two chemical states, with concomitant mitochondrial damage. The majority of debris contained $\mathrm{Cr}^{3+}$, with trace amounts of oxidised cobalt. A minority phase containing a core of metallic chromium and cobalt was also observed.

One million hip replacements are performed annually. In the United States, one third of these use metal-on-metal (MOM) bearings. ${ }^{1}$ Unfortunately, recent evidence suggests that these hips have a higher, early failure rate than predicted ${ }^{2}$ and double that of the other commonly used bearings types: metal on polyethylene and ceramic on ceramic. ${ }^{3,4}$ It is hypothesised that poor human biocompatibility with nanoscale wear debris is responsible for the early failure of MOM hips, ${ }^{5}$ including hip resurfacings. ${ }^{6}$ However, it is not known how wear debris interacts with the tissue, nor which metallic species - in terms of either physical or chemical properties - is responsible for the exaggerated inflammation linked with failure of these devices. $^{5,7,8}$

The oxidation state of the material can provide vital clues to the inflammatory response (such as the generation of oxidising species), as well as providing valuable clinical information on the possible release of $\mathrm{Co}^{2+}$ or $\mathrm{Cr}^{6+}$. CoCr nanoparticles may affect damage across intact cellular barriers through the action of released $\mathrm{Co}^{2+} \cdot{ }^{9}$ However, few techniques are capable of probing the exact chemical state of these particles with sufficient spatial resolution. Chemical analysis has mostly been limited to techniques such as energy dispersive X-ray (EDX) analysis and Fourier transform infrared spectroscopy (FTIR), and hard X-ray specroscopy, however these methods are limited by their combined spatial and energy resolution. ${ }^{10-16}$

${ }^{a}$ Department of Materials, Imperial College London, London, UK

${ }^{b}$ Department of Orthopaedics, Royal National Orthopaedic Hospital, UK

${ }^{c}$ Canadian Light Source, Saskatoon, Canada

${ }^{d}$ FEI Company, The Netherlands \& USA

${ }^{e}$ Centre for Clinical Orthopaedics, University College London, London, UK

${ }^{f}$ Charing Cross Hospital, Imperial College London, London, UK

${ }^{g}$ Department of Materials Science \& Engineering,

The Ohio State University, USA

$\dagger$ Electronic supplementary information (ESI) available: Experimental details and supplementary figures. See DOI: 10.1039/c2cc33016d
In this study X-ray absorption spectroscopy (XAS) and electron energy-loss spectroscopy (EELS) were used in combination to probe electronic structure. Analogous quantitative information on the oxidation state and local coordination environment of the elements can be obtained, although at different spatial and energy resolutions. XAS was performed in the scanning transmission X-ray microscope (STXM) with a spatial resolution of $25 \mathrm{~nm}$ and an energy resolution of $0.1 \mathrm{eV}$. Scanning transmission electron microscopy (STEM)-EELS provided a higher spatial resolution $(<1 \mathrm{~nm})$ and permitted simultaneous acquisition of the $\mathrm{O}, \mathrm{Cr}$ and $\mathrm{Co}$ edges with an energy resolution of $0.7 \mathrm{eV}$. In this contribution we show that a direct correlative spectromicroscopy approach can be used to obtain detailed chemical and morphological characterization of wear particles in explanted human tissue.

The selected patient had previously undergone hip resurfacing arthroplasty (DePuy Articular Surface Replacement made from ASTM F75 alloy: Co, 28 at $\% \mathrm{Cr}, 6$ at $\% \mathrm{Mo}^{16}$ ), which had to be revised after 42 months due to squeaking, clicking and painful hip movements. In addition, the patient's blood levels exhibited extremely high metal content: [Cr] $136.0 \mathrm{ppb}[\mathrm{Co}] 328.5 \mathrm{ppb}$ (high blood metal levels are typical of these patients). Tissue from the hip capsule was collected during revision surgery and a cross section of the surface adjacent to the synovial fluid was studied. Histological examination (Fig. SI1) showed a subsurface band of macrophages that has been typically observed in these patients. ${ }^{16}$ Dark regions of up to $1 \mu \mathrm{m}$ in diameter were observed within the macrophages.

EM imaging revealed that the tissue contained many macrophage cells within the collagen fibre matrix of the capsule (Fig. 1). Most macrophages appeared to be packed with electron dense particles. Their mitochondria appear swollen with a matrix that is more electron lucent than that of control mitochondria and some cristae appear vacuolated (Fig. 1b). These findings are consistent with the effects of oxidant stress. ${ }^{17}$ The observation that $\mathrm{CoCr}$ particles cause mitochondrial toxicity in the absence of cytotoxicity has been reported in fibroblast cells in cell culture experiments. 9 Additionally, a few macrophages were observed to have abnormal nuclear membrane structure, where the outer nuclear membrane is separated from the inner membrane (Fig. 1a). Wear debris was mostly present in two morphologies: dense rounded nanoparticles and diffuse material. Debris was clustered in regions of 


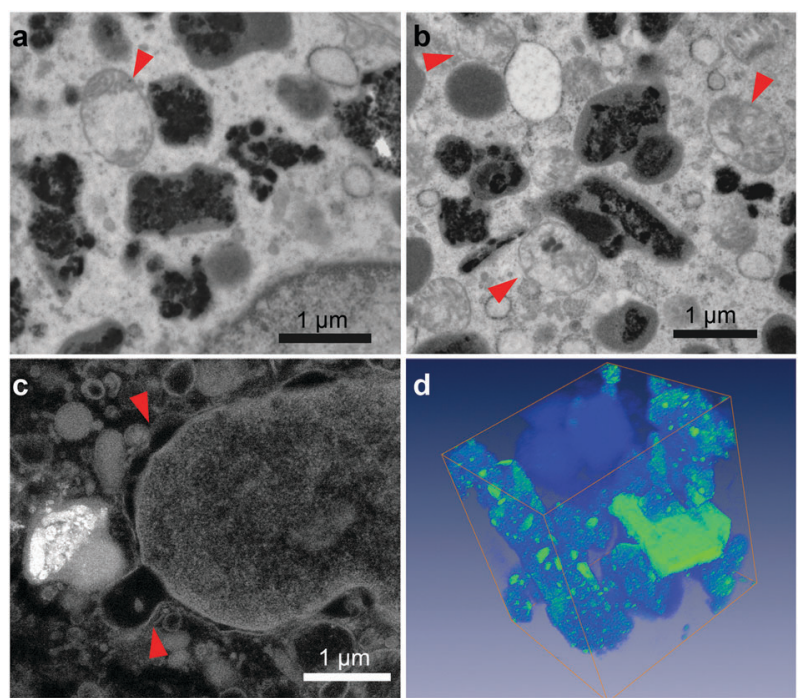

Fig. 1 Electron micrographs of macrophages containing wear debris (a-b) Bright field TEM images show electron dense debris (dark particles) and damaged mitochondria (arrows). (c) HAADF-STEM imaging reveals abnormal nuclear membrane structure (arrows) (d) 3D reconstruction of a volume within a cell, where wear debris appears green.

typically $1 \mu \mathrm{m}$ in diameter. Some high aspect ratio 'needles' of up to $5 \mu \mathrm{m}$ in length were also observed. In agreement with previous studies, TEM-EDX spectra showed that the debris was composed mainly of $\mathrm{Cr}^{10,11,14}$ (Fig. SI2). A 3D reconstruction of a macrophage cell, from dual beam slice and view, confirmed that the particles were internalised inside membrane bound compartments inside macrophage cells (Fig. 1c). Both diffuse and particulate debris were visible in SEM micrographs; the latter were quantified and the particles were found to occupy a moderately large proportion $(12 \% \pm 2 \%)$ of the cell volume. Particles had a large size distribution, from a few nanometres to a few micrometres, with a mean diameter of $30 \mathrm{~nm}$, and a mean aspect ratio of 1.8. In most cases the particles were spherical in morphology with one particle which was plate-like in 3-D (See video of the S\&V data: suppl $\dagger$ ).

Chemical speciation was performed to assess whether debris composition had been altered from that of the original alloy (Fig. 2). STXM-XAS data were obtained by collecting a series of images at different photon energies corresponded to the $\mathrm{Cr}$ and $\mathrm{Co} \mathrm{L}_{2,3}$-edges. Analysis of the resulting datasets allowed characteristic chemical components to be identified (Fig. 2d and e). The spatial distribution of each component was calculated and displayed in a chemical thickness map (Fig. 2b and c). In all areas studied, three phases with distinct chemical fingerprints were identified. Phase 1 contained no detectable $\mathrm{Cr}$ or $\mathrm{Co}$ and corresponded to the cell cytoplasm. Phases 2 and 3 contained both Co and $\mathrm{Cr}$ and corresponded to particles. To determine the valence of the metal species in both phases, the experimental spectra were compared to reference spectra. Comparing positions of edge onsets, $\mathrm{L}_{3} / \mathrm{L}_{2}$ intensity ratios and fine structure, the $\mathrm{Cr}$ species in phase 2 corresponds most closely to $\mathrm{Cr}^{3+}$, in the form of a hydroxide or oxy-hydroxide species (Fig. 2d). Trace amounts of oxidised Co was also present. The large shift in edge onset suggests that the Co is in the $2+$ oxidation state, possibly cobalt phosphate,
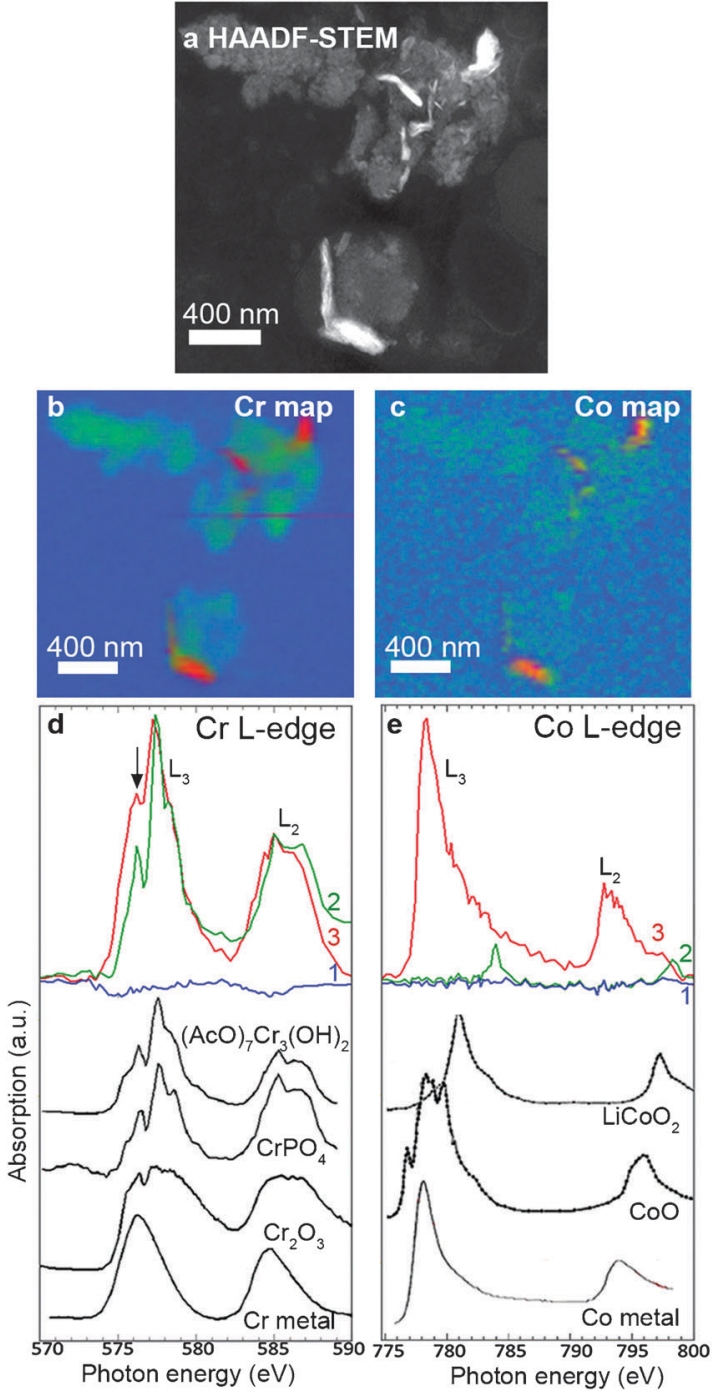

Fig. 2 Clusters of wear debris analysed by STXM and dark field STEM. (a) HAADF-STEM image of debris and corresponding STXM maps of (b) Cr and (c) Co speciation. Three distinct chemical phases, blue green and red, were identified in each dataset. (d, e) XAS spectra of the three chemical phases present in the tissue, compared with reference compounds.

as similar shifts in binding energy have been observed for these compounds in XPS studies. ${ }^{18}$ The $\mathrm{Cr} \mathrm{L}_{2,3}$-edge of phase 3 was very similar to that of phase 2 , suggesting that this phase contained significant amounts of $\mathrm{Cr}^{3+}$. However, in this case the spectrum is best recreated by a linear regression fit of phase 2 and $\mathrm{Cr}$ metal (i.e. $\mathrm{Cr}^{0}$ ) in the ratio $70: 30$. The $\mathrm{Co} \mathrm{L}_{2,3}$-edge in phase 2 matches Co metal. In summary, phase 2 contained $\mathrm{Cr}^{3+}$ and trace amounts of oxidised $\mathrm{Co}$, while phase 3 contained oxidised $\mathrm{Cr}$ as well as metallic $\mathrm{Cr}$ and $\mathrm{Co}$.

Direct comparison of STXM chemical maps with corresponding dark field STEM images (Fig. 2a) revealed that the oxidised debris in phase 2 had diffuse morphology whereas regions which also contained metallic $\mathrm{Cr}$ and $\mathrm{Co}$ corresponded to dense particles with high aspect ratios. STEM-EDX and EELS analysis of the wear debris largely confirmed the STXM results (Fig. 3). Additionally, using STEM-EDX techniques it was also possible to map elemental distributions of Mo 

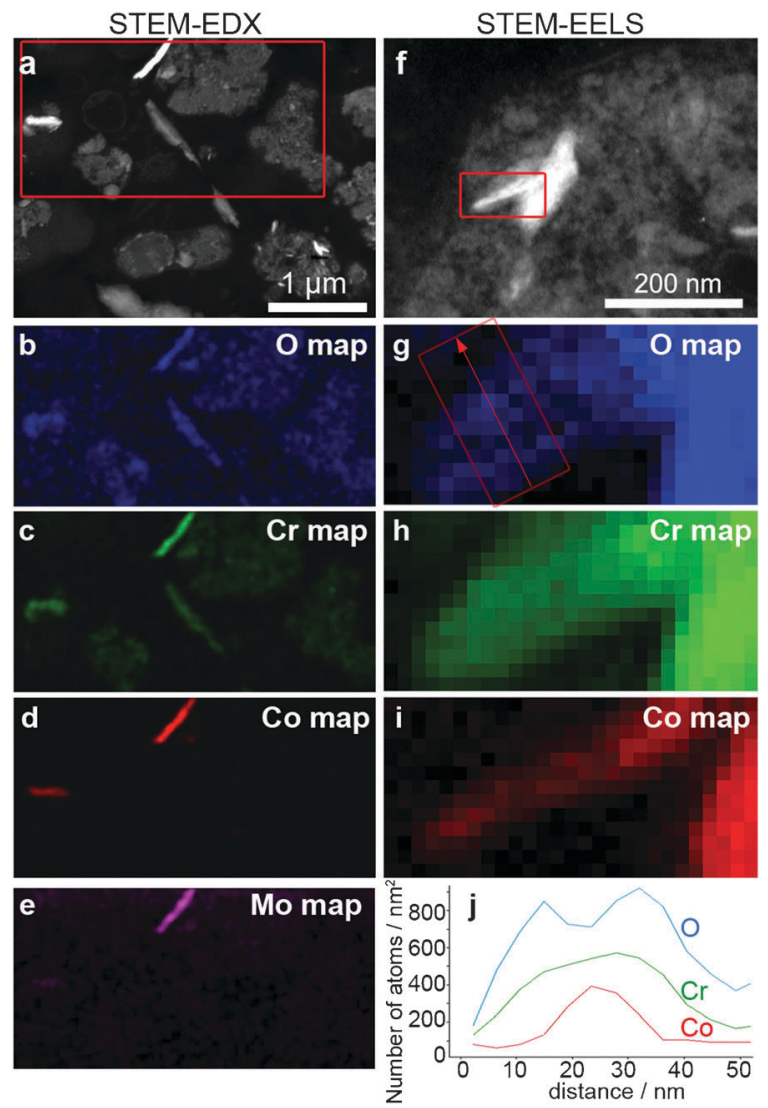

Fig. 3 STEM-EDX and STEM-EELS analysis of wear debris in an adjacent area of cell. (a) HAADF-STEM image and corresponding EDX maps of elemental O, Cr, Co and Mo (b-e). (f) HAADF-STEM image of nanoparticles over which spatially resolved EELS data were acquired (boxed area). Chemical maps of the distribution of elemental $\mathrm{O}, \mathrm{Cr}$ and $\mathrm{Co}$ were calculated ( $\mathrm{g}-\mathrm{i}$ ). (j) Plot of absolute numbers of atoms per unit area, as a function of distance through the nanoparticle (red arrow, Fig. 3g), showing that particle edges are O-rich and Co-deficient.

throughout the debris, as well as the $\mathrm{Cr}$ and $\mathrm{Co}$ studied previously. Correlation of STXM and STEM-EDX maps revealed that Mo is absent from the oxidised debris in phase 2. Mo was only observed in a minority of particles, co-localised with metallic Co (Fig. 3e). The higher spatial resolution of STEM-EELS revealed that single phases in the STXM data are in fact more complex (Fig. 3). EELS studies allowed changes in the chemical composition to be quantified and mapped across a $50 \mathrm{~nm}$ particle. While $\mathrm{Cr}$ and $\mathrm{Co}$ are present throughout the particle, as was evident in the X-ray data, now an O-rich, Co-deficient shell can be observed surrounding the particle.

In summary, two types of wear debris, a diffuse phase containing mainly $\mathrm{Cr}^{3+}$ with trace amounts of oxidised $\mathrm{Co}$, as well as dense core-shell particles containing metallic $\mathrm{Co}, \mathrm{Cr}$ and Mo surrounded by $\mathrm{Cr}^{3+}$ have been detected. The majority of particles internalized inside macrophages were near-devoid of Co suggesting that prolonged release of $\mathrm{Co}^{2+}$ in the cellular environment, as a result of the continuous generation of wear debris particles. The near-absence of Co from the majority of the debris suggests that particles undergo rapid corrosion in the tissue. $\mathrm{Co}^{2+}$ is extremely soluble under normal physiological conditions and is readily transported into the blood stream and subsequently excreted; in the bulk alloy it is normally protected from corrosion by the passivating effect of the $\mathrm{Cr}$. Some particles however do contain residual Co, Mo and $\mathrm{Cr}$ in their original metallic state; most likely these particles were undergoing corrosion before the tissue was removed and fixed. The probability of finding such particles is low and strongly depends on the time between particle generation and the revision surgery, as well as how the tissue/particle structure is preserved during analysis. Whilst a lot of concern has focussed on the potential generation of the genotoxic $\mathrm{Cr}^{6+}$, our data suggest a significant localised release of $\mathrm{Co}^{2+}$ which is known to be genotoxic. ${ }^{9}$ This overt release of $\mathrm{Co}$, not seen in the bulk material, is probably repsonsible for the inflammatory response and suggests that simple measurement of the corrosion behviour of the bulk material is not adequate for device development. The success of this approach has implications for a host of other systems in which the chemical speciation of nanoparticles may be linked to tissue function.

Funding was provided by EPSRC Science and Innovation Programme: EP/D063329; and ERC starting investigator grant \#257182 (AEP). The London Implant Retrieval Centre is funded by the British Orthopaedic Association (see suppl. $\dagger$ ).

\section{References}

1 K. J. Bozic, S. Kurtz, E. Lau, K. Ong, V. Chiu, T. P. Vail, H. E. Rubash and D. J. Berry, J. Bone Jt. Surg., 2009, 91, 1614-1620.

2 W. T. Long, M. Dastane, M. J. Harris, Z. Wan and L. D. Dorr, Clin. Orthop. Relat. Res., 2009, 468, 400-405.

3 Annual Report, Australian Orthopaedic Association National Joint Replacement Registry, 2009.

4 6th Annual Report, National Joint registry for England and Wales, 2009.

5 H. G. Willert, G. H. Buchhorn, A. Fayyazi, R. Flury, M. Windler, G. Koster and C. H. Lohmann, J. Bone Jt. Surg., 2005, 87, 28-36.

6 A. J. Hart, S. Sabah, J. Henckel, A. Lewis, J. Cobb, B. Sampson, A. Mitchell and J. A. Skinner, J. Bone Jt. Surg., 2009, 91B, 738-744.

7 A. P. Toms, T. J. Marshall, J. Cahir, C. Darrah, J. Nolan, S. T. Donell, T. Barker and J. K. Tucker, Clin. Radiol., 2008, 63, 49-58.

8 W. C. Witzleb, U. Hanisch, N. Kolar, F. Krummenauer and K. P. Guenther, Acta Orthop., 2007, 78, 211-220.

9 G. Bhabra, A. Sood, B. Fisher, L. Cartwright, M. Saunders, W. H. Evans, A. Surprenant, G. Lopez-Castejon, S. Mann, S. A. Davis, L. A. Hails, E. Ingham, P. Verkade, J. Lane, K. Heesom, R. Newson and C. P. Case, Nat. Nanotechnol., 2009, 4, 876-883.

10 I. Catelas, J. B. Medley, P. A. Campbell, O. L. Huk and J. D. Bobyn, J. Biomed. Mater. Res., 2004, 70B, 167-178.

11 B. F. Shahgaldi, F. W. Heatley, A. Dewar and B. Corrin, J. Bone Jt. Surg., 1995, 77B, 962-966.

12 C. Brown, S. Williams, J. L. Tipper, J. Fisher and E. Ingham, J. Mater. Sci.: Mater. Med., 2007, 18, 819-827.

13 E. Chassot, J. L. Irigaray, S. Terver and G. Vanneuville, Med. Eng. Phys., 2004, 26, 193-199.

14 M. Huber, G. Reinisch, G. Trettenhahn, K. Zweymuller and F. Lintner, Acta Biomater., 2009, 5, 172-180.

15 R. M. Urban, J. J. Jacobs, J. L. Gilbert and J. O. Galante, J. Bone Jt. Surg., 1994, 76, 1345-1359.

16 A. J. Hart, P. D. Quinn, B. Sampson, A. Sandison, K. D. Atkinson, J. A. Skinner, J. J. Powell and J. F. W. Mosselmans, Acta Biomater., 2010, 6, 4439-4446.

17 M. Akao, B. O'Rourke, Y. Teshima, J. Seharaseyon and E. Marban, Circ. Res., 2003, 92, 186-194.

18 C. Carrara, S. Irusta, E. Lombardo and L. Cornaglia, Appl. Catal., A, 2001, 217, 275-286. 